Journal of Animal and Veterinary Advances 10 (1): 87-91, 2011

ISSN: $1680-5593$

(C) Medwell Journals, 2011

\title{
Affecting the Choice Factors of Fishery Products Consumption in Turkey
}

\author{
Saygi Hulya and Hekimoglu Muge Aliye \\ Department of Aquaculture Technology, Faculty of Fisheries, Ege University, Bornova-Izmir, Turkey
}

\begin{abstract}
This study examines fish consumption behavior patterns. The aim of this study was to evaluate the importance of choosing factors in determining food pattern of Turkish people. A total of 666 surveys in all around Turkey responded to a self-administered questionnaire about seafood consumption habits, past frequency of seafood consumption, attitude towards and intention to eat seafood. In this research some prompts were used such as health, taste, availability, versatility, the components of a good family meal, value for money and alternatives to red meat.
\end{abstract}

$\underline{\text { Key words: Fishery products, consumption, factor analysis, meal, alternatives, Turkey }}$

\section{INTRODUCTION}

Fishery production as well as eliminating the need for animal protein is one of the most important food source for human nutrition. The population increases as a continuous increase but production potential is not unlimited; the per capita amount of water the product will begin to decrease after a certain level of consumption and production will be limited to the consumption amount. Studies on consumption of seafood has increased in the last 20 years. More studies have focused on fish consumption.

But in them only for consumption is to be determined (Cokyuce, 1993; Saygi et al., 2006; Leek et al., 2000). Besides, factor analysis of the study had been done by determining fish consumption (Leek et al., 2000). In other study of the factors affecting consumption have used multiple regression analysis (Senol and Saygi, 2001). Food consumption behaviour like any complex human behaviour will be influenced by many interrelating factors, like physical properties of the food, characteristics of the individual or characteristics with the environment (Shepherd, 1989).

In this study, an exploratory investigation of the ways is described in which fish consumption is situationally determined. The categories of situational outcome of consumption behaviour identified by the behavioural perspective model (Foxall, 1990) are employed as a frameresearch within which the historical and tepporal contexts of fish purchase and non-purchase can be understood (Leek et al., 2000). A questionnaire which concentrated exclusively on these factors would of course find evidence for the model and concentrated on the full range of factors likely to result in purchase and consumption of fish. The study proceed, therefore, on the understanding that the structure of respondents verbal evaluations of fish purchase, prepararation and consumption would provide an index of the relevance of the BPM to the analysis of consumer behaviour in Turkey.

\section{MATERIALS AND METHODS}

Questionnaire design: The questionnaire opened with protocal for the interviewer which explained what the research was about who was conducting it and requesting participation in the study. A screening question followed which idendified individuals who purchased food for their family. The first section of the questionnaire investigated past fish purchasing behaviour. It examined the frequency of fish purchasing in general. Six answer options were provided:

- More than once a week

- Once a week

- Once a fornight

- Less than once a month

- Never

If the respondent answered never, he/she was filtered to the next section on future fish purchasing behaviour. In the second section of the quastionare measured the respondent's attitudinal beliefs with respect to fish. It consisted of 17 attitude statements which took into account both the positive and negative perceptions of fish which were found in previous research to influence the purchase of fish and its associated products:

Corresponding Author: Hulya Saygi, Department of Aquaculture Technology, Faculty of Fisheries, Ege University, Bornova-Izmir, Turkey 
- Fish is a healthy food

- Fish is diffucult to prepare

- Fish makes a good family meal

- Fish provides an alternative to red meat

- Fish can be used in many different recipes

- Fish is readily available in the shops

- Fish goes off quickly

- The bones in fish are off-putting

- Fish provides good value for money

- I prefer chicken

- I like to serve fish when I have guests

- Fish is nutritious food

- Fish is expensive

- There are lots of different varieties of fish

- There is a danger of food poisoning

- Fish has an unplesant smell

- $\quad$ Fish is versatile (Leek et al., 2000)

Respondents indicated their degree of agreement or disagreement with each attitude statemnet on a sevenpoint scale ( 1 , strongly disagree; 2 , disagree; 3 , slightly disagree; 4 , neutral; 5 , slightly agree; 6 , agree; 7 , strongly agree). The belief statements reflect the three consequences of purchasing and consuming fish. Utility is indicated by statements 2 (fish is diffucult to prepare), 5 (fish can be used in many different recipes), 6 (fish is readily available in the shops), 12 (fish is nutritious food), 14 (there are lots of different varieties of fish) and 17 (fish is versatile). Symbolic rewards are apparent in statements 1 (fish is a healthy food), 3 (fish makes a good family meal), 4 (fish provides an alternative to red meat), 10 (I prefer chicken) and 11 (I like to serve fish when I have guests). Finally, costs were considered in statements 7 (fish goes off quickly), 9 (fish provides good value for Money), 13 (fish is expensive), 15 (there is a danger of food poisoning) and 16 (fish has an unplesant smell).

Procedure: The main mass of data collected to examine the entire time and cost in terms of negativity is going to lead the way for sampling. Turkey's population constitutes the main audience for this purpose. According to the Turkey population, the random call method was used to obtain a sample of 666 respondents selected Turkish Internet panel company under whose guidance the questionnaires were completed. Individuals had become a panel member in the past on the web-site of http:www.sureforms.net/seafood.form. By becoming a panel member they indicated their willingness to participate in various types of online research (e.g., online surveys or opinion polls) on all kinds of different topics (e.g., politics, marketing research, health issues). Respondents are not precontacted but questionnaires are usually sent immediately to a selected sample. Respondents were representative of the Turkey population in terms of age, socio-economic class, employment status and region. In the present study, a total of 750 adults, randomly selected from the total panel were invited to participate. They were sent an email letter explaining the study details with a link to the electronic questionnaire. According to this survey between September 2009-November 2009 were submitted. In this study, 666 people have been used from the current survey. The data obtained were analyzed by SPSS 18.0 package program. For analyzing data was used some Statistical techniques such as $\chi^{2}$-test, the Kaiser-Meyer Olkin (KMO) test, Barlet test, factor analysis.

\section{RESULTS AND DISCUSSION}

In this study, $81 \%$ of participants are consumed seafood and those who consumed $47.7 \%$ of fish consumed fortnightly.

Table 1 showed fish consumption related age, sex, etc., conducive to the application of the variables used in factor analysis to determine whether the Kaiser-MeyerOlkin (KMO) 0862 results were calculated. Barlett's Test of sphericity value also $\left(\chi^{2}=16553.991 ; \mathrm{p}=0.000\right)$ and the significance of each of the variables did not show a correlation between the test and factor analysis of the data used to show whether or not to do. In the two values was used for data analysis showed.

Table 1: Demographic characteristics associated with fish consumption

\begin{tabular}{|c|c|c|c|c|}
\hline Parameters & Frequency & $\%$ & $\chi^{2}$ & p-value \\
\hline Age & - & - & 17.272 & 0.002 \\
\hline Below 20 & 118 & 17.7 & - & - \\
\hline $21-30$ & 153 & 23.0 & - & - \\
\hline $31-40$ & 209 & 31.4 & - & - \\
\hline $41-50$ & 105 & 15.8 & - & - \\
\hline $51+$ & 81 & 12.2 & - & - \\
\hline Sex & - & - & 8.532 & 0.003 \\
\hline Male & 229 & 34.4 & - & - \\
\hline Female & 437 & 65.6 & - & - \\
\hline Occupation & - & - & 70.669 & 0.000 \\
\hline Retired & 2 & 0.3 & - & - \\
\hline Tradesman & 33 & 5.0 & - & - \\
\hline Officer & 229 & 34.4 & - & - \\
\hline Labour & 22 & 3.3 & - & - \\
\hline Self-employment & 222 & 33.3 & - & - \\
\hline Student & 106 & 15.9 & - & - \\
\hline Others & 52 & 7.8 & - & - \\
\hline District & - & - & 10.152 & 0.000 \\
\hline Coastal & 380 & 57.1 & - & - \\
\hline Inland & 286 & 42.9 & - & - \\
\hline Education & - & - & 25.899 & 0.000 \\
\hline Primary & 58 & 8.7 & - & - \\
\hline Secondary & 211 & 31.7 & - & - \\
\hline Higher education & 323 & 48.5 & - & - \\
\hline Masters and $\mathrm{PhD}$ & 74 & 11.1 & - & - \\
\hline Total & 666 & 100.0 & - & - \\
\hline
\end{tabular}


Table 2: Four-factor model

\begin{tabular}{lcccc}
\hline Parameters & Factor I & Factor II & Factor III & Factor IV \\
\hline Nutritious & 0.805 & - & - & - \\
Used in many different & 0.807 & - & - & - \\
recipes & & & & \\
Value for money & 0.854 & - & - & - \\
Healthy & 0.684 & - & - & - \\
Lots of different varieties & 0.870 & - & - & - \\
Difficult to prepare & - & 0.636 & - & - \\
Bones are off-putting & - & 0.608 & - & - \\
Prefer chicken meat & - & 0.884 & - & - \\
Expensive & - & 0.884 & - & - \\
Alternative to red meat & - & - & 0.848 & - \\
Good family meal & - & - & 0.872 & - \\
Readily available & - & - & 0.865 & - \\
Serve fish when I have guests & - & - & 0.730 & - \\
Versatile & - & - & 0.776 & - \\
Goes off quickly & - & - & - & 0.715 \\
Danger of food poisoning & - & - & - & 0.891 \\
Unpleasant smell & - & - & - & 0.905 \\
\hline
\end{tabular}

In order to establish whether the structure of consumers beliefs corresponded to the components of the $\mathrm{BPM}$, principal component factor analysis with varimax rotation was performed on the survey data (Hackett and Foxall, 1999) and produced a solution of four factors with Eigen values greater than unity. Inspection of a scree plot of eigen values confirmed that these four factors should be included in the analysis. These four factors, taken together accounted for almost $87 \%$ of the cumulative variance:

- $\quad$ Factor $1($ Eigen value $=9.154)$ accounted for $53.850 \%$

- Factor 2 (Eigen value $=3.124)$ accounted for $18.377 \%$

- Factor 3 (Eigen value $=1.321$ ) accounted for $7.773 \%$

- Factor 4 (Eigen value $=1.125$ ) accounted for $6.619 \%$

Table 2 shows the listing of the variables which load on the significant factors. In line with the range of acceptable criteria levels noted. A factor loading of 0.5 has been used to determine the cut-off point for assigning variables to factors (Child, 1970; Kim and Mueller, 1978; Norusis, 1988; Leek et al., 2000). Factor I, versatility, encompasses the ease of preparation and the versatility of fish in its ability to be incorporated into a number of recipes consists of statements referring to price and value for money. Factor II, negativity, embraces the unappealing qualities of fish: the bones, the smell, the perceived potential danger of food poisoning and the fact that fish goes off quickly. Factor III, appropriateness refers mainly to the situations in which fish is used, i.e., as a good family meal as an alternative to the usual red meats and for serving to guests. Finally, Factor IV, convenience which is included in this exploratory analysis despite its consisting of a single variable refers to the availability of fish. In that research, conducted by a professional market research firm, respondents were asked what made them buy fish and a number of prompts were used: health; taste; availability; versatility; the components of a good family meal; value for money and alternatives to red meat. Barriers to fish consumption such as difficulty of preparation, expense, taste, smell, the bones and the short storage life were all discussed. Respondents were asked whether they felt more or less confident when choosing, buying, preparing, cooking and serving fish than when meat or poultry were involved.

\section{CONCLUSION}

Food demand and consumption habits of a society of products quality, price and hygiene specifications, the country's income distribution, consumer education, income level, etc., to differences in socio-economic characteristics as well as those of race, gender, age, activity status, related nutrition information and can vary depending on factors such as experience and has a complex structure (Stefanikova et al., 2006). Than human beings in the womb while the $\omega-3$ fatty acids and the need to increase this requirement at every stage of life continues. For it is not only children and the elderly people in all age groups especially mothers with at least two meals of fish per week are required to eat. This is essential for a healthy life. In the age, the death of $>50 \%$ of heart attacks, arteries, high cholesterol and cancer related diseases caused by the depression, stress, violence, suicide cases much increase is considered, fish consumption, the importance of even the best will be understood. Optimal development of public health importance of nutrition and health is well known. Optimal nutrition standards in the American Heart Association and Turkey, the relevant institutions and organizations also suggested a week at least 300-450 $\mathrm{g}$ of fish consumption and a very chronic disease prevention and therefore protection of health and development as an important step is considered.

Those who consumed fish, consumed in food oils, rich in unsaturated fats that are very important. Because $\omega-3$ series fatty acids in the body, important role in biochemical and physiological activities that are now known exactly. The aquatic species rich in polyunsaturated fatty acids had protective effects against cardiovascular disease (Scholderer and Trondsen, 2008). Fatty acids in the human body, eyes, brain, testes and placenta are collected. Your eyes are researching properly and fully perform the functions of the brain helps.

Regulates the concentration of fat in the blood (Gordan and Ratliff, 1992). As a result, these fatty acids, heart attack, cardiovascular disease, depression, migraine type headaches, joint rheumatism, diabetes, high 


\section{J. Anim. Vet. Adv., 10 (1): 87-91, 2011}

cholesterol and blood pressure, certain allergic types of cancer many diseases in the prevention of significant effects were found (Gorga, 1998; Nettleton, 1992; Kaya et al., 2004). Problems do not consume fish, fish is low in saturated fats, high in nutrients, readily available. But while it is second only to chicken as a sourche of protein, it is stil not regularly consumed by most of the population. While meat and fish are the two main sources of protein (Leek et al., 2000; Key, 1996), meat is more popular than fish in spite of general consumer beliefs to the effect that red meat, in particular may have unhealthy properties (Leek et al., 2000; Foxall and Haskins, 1986). People may be averse to consuming fish because of a perceived difficulty in buying, preparing and cooking it, the belief that it is expensive or the unpleasant physical properties of some varieties of fish such as bones and the smell (Leek et al., 2000; Connell, 1987; Goulding, 1985).

An emprical investigation of the structure of beliefs towards fish is reported and show how each of the belief components identified contributed to explaining the purchase of fish as a whole. Discussion of the method and results is prefaced by an account of the current knowledge about consumers perceptions of fish products and the incorporation of both sets of findings into the questionnaire on which the quantitative exploration was founded. Against fish behaviour, fresh fish generates both the strongest negative beliefs and the strongest positive beliefs of the product class. In Turkey seafood consumption preferences factors affecting reveal aimed desired conclusion, according to the water product marketing and consumption is still at a desired level an effect or not, no seafood consumed a part of the well is located has emerged. Researching conditions of the region are taken into consideration due to geographical features and economic conditions and unknown types of seafood are consumed. To raise awareness of consumers, the quality of aquatic products, feed consumption and economy information about the value must be explained to consumers. Local authorities and other regional institutions and organizations in their area of interest to the public water products and promotional activities should be encouraging. Consumption in Turkey promote and encourage expansion of activities in the market, recruiters must be required to increase consumption.

Study fish farming in the context of individuals in Turkey were studied to determine consumption habits. Low levels of fish consumption rates in the survey appears to be. Likewise, in terms of frequency of consumption by $90 \%$ in one group consumed only a few days to fish, fish as a nutritional approach to reveal. That the underlying economic causes, although, the consumption habits of the Turkish people tend to push the red meat is more severe. The average annual consumption of $9.16 \mathrm{~kg}$ of red meat is thought to be the trend is more clearly revealed. However, the average annual consumption of chicken is believed to be $3.14 \mathrm{~kg}$ of chicken meat is also a price advantage against fish is emerging. Another issue is the criteria for the taste of fish culture. In the natural environment that has many different food choices of individuals, culture, environment, nutrition and the standard feed is the main source of this problem. About $62 \%$ of those surveyed prefer to fish culture instead of the natural environment but also in terms of price differences in culture and natural environment of fish is 2.5-3 times the inverse relationship between consumption and demand is created. However, the age of the food supply with food prepared in accordance with the technical research has risen considerably in the criteria of taste, nutritional composition of fish, fish habitat from time to time are found to be higher (Cakli et al., 2005).

The research reported here confirms that situational influences on consumer behaviour can be comprehended in terms of the components of the Behavioural perspective model: consumer behaviour setting, learning/consumption history, utilitarian reinforcement, informational reinforcement and aversive consequences. Economic theory suggests that the main determinants of changes in food consumption are changes in real consumer income, in product price and in the prices of complementary and substitute goods as well as preferences and sociodemographic factors. With a decreasing share of food in total expenditure however, income and prices have become less significant as explanatory variables while sociodemographic factors as well as preferences have gained in importance (Elsner and Hartmann, 1998). As a result, increasing fish consumption habits of today's society and future generations, creating healthy is an essential phenomenon. In this situation about being periodically updated by aquaculture production should be supported and that these products consumption on human health over the short and long term benefits (against cancer effects, cardiovascular health, diabetes delayed, depression, aging, memory loss, inflammation and migraine pain prevention) should be explained. Within the education system and value the importance of seafood in a family environment for children should be told, starting from primary school level students definitions of fishery products should be transferred to the theoretical and practical. In addition, we have resources and sustainable production processes with the implementation of 500 thousand tons of fish produced per year and in this regard would be possible obtaining healthy food should not be forgotten to may rise from the center of the problem. 


\section{REFERENCES}

Cakli, S., T. Dincer, A. Cadun, K. Firat and S. Saka, 2005. Quality characteristics of wild and cultured common dentex (Dentex dentex L. 1758). Archive fur Lebensmittelhygiene, 56: 105-108.

Child, D., 1970. The Essentials of Factor Analysis. Holt, Rinehart and Winston, London.

Cokyuce, M., 1993. Gilthead Sea Bream Operations in South Aegean Region, Gilthead Sea Bream Marketing Problems and Proposals. Ege University, Ozmir, pp: 33-49.

Connell, J.J., 1987. New developments in the marketing of fish. Food Marketing, 3: 118-129.

Elsner, K. and M. Hartmann, 1998. Convergence of food consumption patterns between Eastern and Western Europe. IAMO Discussion Paper No. 13, Halle/Saale. http://www.econstor.eu/dspace/handle/10419/28587.

Foxall, G.R. and C.G. Haskins, 1986. Cognitive style and consumer innovativeness: An empirical test of kirton's adaption-innovation theory in the context of foof purchasing. Eur. J. Marketing, 20: 63-80.

Foxall, G.R., 1990. Consumer Psychology in Behavioural Perspective. Routledge, London and New York.

Gordon, D.T. and V. Ratliff, 1992. The Implications of Omega 3 Fatty Acids in Human Health. In: Advances in Seafood Biochemistry Composition and Quality, Flick, I.G.J. and R.E. Martin (Eds.). Technomic Publishing Co. Inc., Lancaster, PA., pp: 69-98.

Gorga, C., 1998. Quality Assurance of Seafood. Van Nostrand Reinhold, New York.

Goulding, I., 1985. Fish marketing in the UK. Food Marketing, 1: 35-56.

Hackett, P. and G.R. Foxall, 1999. A Factor Analytic Study of Consumers Location Specific Values: A Traditional High Street and A Modern Shopping Mall. In: Quantitative Methods in Marketing, Hooley, G.J. and M.K. Hussey (Eds.). International Thomson Business Press, London, pp: 317-336.
Kaya, Y., H.A. Duyar and M.E. Erdem, 2004. The importance of fish fatty acids on human health. J. Fish. Aquat. Sci., 21: 365-370.

Key, N., 1996. Key Note Report on Fish and Fish Products. Key Note Publications, London.

Kim, J.O. and C.W. Mueller, 1978. Factor Analysis: Statistical Methods and Practical Issues. Sage, London.

Leek, S., S. Maddock and G. Foxall, 2000. Situational determinants of consumption. Br. Food J., 102: 18-39.

Nettleton, J.A., 1992. Seafood Nutrition in the 1990: Issues for the Consumer. In: Seafood Science and Technology, Bligh, E.G. (Ed.). Fishing News Books, London, pp: 32-39.

Norusis, M.J., 1988. SPSS/PC+ Advanced Statistics. Version 2. SPSS Inc., Chicago, IL.

Saygi, H., S. Saka, K.Firat and T. Katagan, 2006. The consumption of fish and approach to fish culture of public opinion in Izmir Central Districts.E.U. J. Fish. Aquat. Sci., 23: 133-138.

Scholderer, J. and T. Trondsen, 2008. The dynamics of consumer behaviour on habit, discontent and other fish to fry. Appetite, 51: 576-591.

Senol, S. and H. Saygi, 2001. Econometric model for seafood consumption, E.U. J. Fish. Aquat. Sci., 18: 383-390.

Shepherd, R., 1989. Factors ?nfluencing Food Preferences and Choice. In: Handbook of the Psychophysiology of Human Eating, Shepherd, R. (Ed.). Wiley, Chichester, London, pp: 3-24.

Stefanikova, Z., L. Sevcikova, J. Jurkovicova, L. Sobotova and L. Aghova, 2006. Positive and negative trends in university students'food intake. Bratisl Lek Listy, 107: $217-220$. 